\title{
Sistemas de alimentação para a recria de ovinos a pasto: avaliação do desempenho animal e características da forragem
}

\author{
Feeding systems for sheep rearing on pasture: evaluation of animal performance and forage \\ characteristics
}

\author{
Marcos da Silva Brum ${ }^{\text {I* }}$ Fernando Luiz Ferreira de Quadros ${ }^{\text {II }}$ Jorge Dubal Martins ${ }^{\text {III }}$

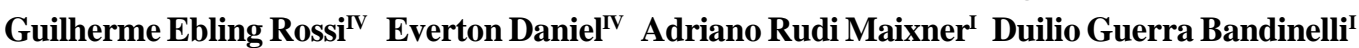

\section{RESUMO}

Um experimento foi conduzido na Fundação Estadual de Pesquisa Agropecuária (FEPAGRO), em São Gabriel, Rio Grande do Sul (RS), com objetivo de avaliar o desempenho de cordeiras em recria, as características da pastagem, a composição química e a cinética de degradação nas alternativas: pastagem cultivada de milheto (Pennisetum americanum (L.) Leeke) (PCM), pastagem natural (PN) e pastagem natural melhorada (PNM), que constituíram os tratamentos. O período de pastejo foi de 29 de janeiro a 14 de abril de 2005, sendo este caracterizado por uma forte estiagem. A PNM apresentou valores médios de massa de forragem superiores aos demais tratamentos, pela grande quantidade de material morto de azevém presente na forragem disponível. A PCM apresentou maior proporção de folhas em relação à $P N$ e à PNM. A carga animal média de $914 \mathrm{~kg}$ de $P V \mathrm{ha}^{-1}$ da $P C M$ foi superior à de $261 \mathrm{~kg}$ de $P V \mathrm{ha}^{-1}$ e de $467 \mathrm{~kg}_{\text {de }} P V \mathrm{ha}^{-1} \mathrm{da}$ $P N$ e da PNM, respectivamente. O ganho médio diário (GMD) no tratamento PCM $\left(0,151 \mathrm{~kg} \mathrm{dia}^{-1}\right)$ foi superior ao da $P N(0,053 \mathrm{~kg}$ dia $\left.^{-1}\right)$ e da PNM $\left(0,058 \mathrm{~kg} \mathrm{dia}^{-1}\right)$, proporcionando maior peso vivo final ( $36 \mathrm{~kg}$ de PV.animal $\left.{ }^{-1}\right)$ e escore corporal final $(3,7$ unidades) na PCM. Foram observados maiores valores de proteína bruta e menores de FDA e FDN na PCM em relação à $P N$ e à PNM. $O$ volume final de gás, a taxa de degradação $e$ o tempo de colonização refletiram com precisão a composição química e os ganhos de peso observados, sendo melhores para a PCM.

Palavras-chave: cordeiras, introdução de leguminosas, milheto, pastagem natural.

\section{ABSTRACT}

A trial was conducted at Fundação Estadual de Pesquisa Agropecuária (FEPAGRO) in São Gabriel, Rio
Grande do Sul (RS), aiming to evaluate female lambs performance in rearing, sward characteristics, the chemical composition and the degradation kinetics of pearl millet (Pennisetum americanum (L.) Leeke) (MP); natural grassland (NG) and natural grassland improved (ING), that constituted the treatments. The grazing period was from January 29 to April 14, 2005, being characterized by a strong drought. ING presented average values of forage mass higher than other treatments, due to the great amount of dead material in the available forage. MP presented larger ratio of leaves in relation to NG and ING. The average stocking rate of $914 \mathrm{~kg}$ of $L W \mathrm{ha}^{-1}$ of

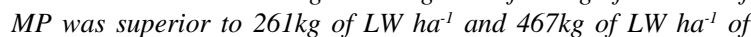
NG and ING, respectively. Average daily liveweight gain (DLG) in treatment MP $\left(0.151 \mathrm{~kg} \mathrm{day}^{-1}\right)$ was superior to $N G(0.053 \mathrm{~kg}$ day $\left.^{-1}\right)$ and ING $\left(0.058 \mathrm{~kg} \mathrm{day}^{-1}\right)$, providing larger final live weight (36kg of LW animal-1) and final body score (3.7 units) in MP. Larger crude protein values and smaller of FDA and FDN was observed in MP in relation to NG and ING. The final volume of gas, the degradation rates and time of colonization were well correlated to the chemical composition and the weight gain accurately observed, being better for MP. Even in situations of adverse climatic conditions, millet pasture demonstrated to be a good alternative to increase the stocking rate and the weight gain in sheep rearing systems in Rio Grande do Sul.

Key words: female lambs, legumes sodseeding, millet, natural grassland.

\section{INTRODUÇÃO}

A recria de ovinos no RS está voltada para a precocidade do desempenho reprodutivo das fêmeas e da idade de abate dos machos. Para atender a esse

\footnotetext{
IPrograma de Pós-graduação em Zootecnia (PPGZ), Universidade Federal de Santa Maria (UFSM), Santa Maria, RS, Brasil. *Endereço para correspondência: Rua Coronel Niederauer, no 814/102, 97015-120, Santa Maria, RS, Brasil. E-mail: marcossbrum@yahoo.com.br.

IIDepartamento de Zootecnia, UFSM, Santa Maria, RS, Brasil.

IIIFundação Estadual de Pesquisa Agropecuária (FEPAGRO), São Gabriel, RS, Brasil.

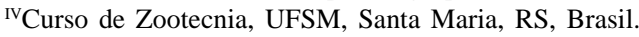


objetivo, é importante o estudo do potencial de produção de ovinos em sistemas alimentares baseados em pastagens, visto que a pastagem é a fonte de nutriente mais barata para os herbívoros.

No RS, estima-se que a superfície de pastagens naturais esteja atualmente em torno de 9 milhões de hectares (CARVALHO et al., 2006), correspondendo a 74\% das áreas destinadas a pecuária de corte. A dependência dos sistemas criatórios pela pastagem natural tenderá a perdurar, ao menos no que diz respeito ao rebanho bovino e ovino de corte, sobretudo para a cria e recria, não só por razões econômicas, mas também ambientais e até paisagísticas (NABINGER, 2006). Esse recurso forrageiro apresenta uma diversidade de espécies bastante grande, sendo conhecidas cerca de 400 espécies de gramíneas e 150 espécies de leguminosas (BOLDRINI, 1997), a maioria delas perenes e de crescimento estival. Trabalhos conduzidos com bovinos demonstraram que essas pastagens naturais permitem desempenho satisfatório dos animais na estação de crescimento. Entretanto, são escassos os trabalhos conduzidos com ovinos em nossas pastagens naturais (NABINGER, 2006).

Com o uso da adubação e a introdução de espécies hibernais por sobre-semeadura em pastagem natural, podem ser obtidos acréscimos significativos na produção de forragem, permitindo maior carga animal, ganho por animal e por área, se comparados com os da pastagem nativa, principalmente no período de inverno, época de maior escassez de forragem (RIZO et al., 2004). Durante o verão, CARÁMBULA (1997) salienta que o pastejo em pastagens melhoradas com introdução de espécies deve ser leve, de tal maneira que permita a sobrevivência das espécies introduzidas. No Uruguai, MONTOSSI et al. (2003) trabalharam com cordeiros cruzas Corriedale $\mathrm{x}$ Texel e Corrielale $\mathrm{x}$ Hampshire Down $x$ Texel em dois tipos de melhoramento de campo com trevo branco (Trifolium repens cv. LE Zapicán) e cornichão (Lotus corniculatus cv. San Gabriel) e outro por cornichão El Rincón (Lotus subbiflorus cv. “El Rincón”). No ano 2000, no período de outubro a dezembro, esses autores observaram valores de GMD de $196 \mathrm{~g}$ dia $^{-1}$ em cordeiros na mistura trevo branco + cornichão e de $212 \mathrm{~g} \mathrm{dia}^{-1}$ na pastagem de cornichão “El Rincón”, o que lhes conferiu peso de abate de 35,3 e 36,4kg, nas mesmas pastagens, respectivamente.

A utilização de pastagens cultivadas de estação fria e de estação quente dentro de sistemas de produção é opção que visa a manter altas produções de matéria seca de qualidade, procurando atender o desempenho animal a baixo custo. Entre as espécies forrageiras utilizadas no RS, na estação estival, destaca- se o milheto por possuir características de alta produção de forragem, com alta qualidade, por suportar cargas animais elevadas e por sua adaptação à diversidade de condições ambientais do Estado (MOOJEN et al., 1999; SANTOS et al., 2005). Em pastagem de milheto manejada com diferentes alturas, CASTRO (2002) observou em cordeiros ganho individual médio de $121,7 \mathrm{~g} \mathrm{dia}^{-1}$ na pastagem com e 33,3cm de altura e ganho por área de 609,3kg de PV ha-1 na altura média de 29,2cm.

Tão importante quanto o estudo do desempenho animal em diferentes sistemas de alimentação baseados em pastagens, é conhecer as características dessas pastagens, já que a heterogeneidade da estrutura das plantas afeta a quantidade e a qualidade da forragem ingerida, determinando diferenças no desempenho dos animais.

O objetivo deste trabalho foi avaliar o desempenho de cordeiras, as características da pastagem, a composição química e a cinética de degradação nas alternativas: pastagem cultivada de milheto, pastagem natural e pastagem natural melhorada com introdução de espécies hibernais.

\section{MATERIAL E MÉTODOS}

O experimento foi conduzido no período de 29/01 a 14/04/2005, em área pertencente ao Centro de Pesquisas de Forrageiras, da Fundação Estadual de Pesquisa Agropecuária (FEPAGRO), em São Gabriel, RS, situado na região fisiográfica da Depressão Central, entre as coordenadas $30^{\circ} 20^{\prime} 27^{\prime}$ 'S e $54^{\circ} 19^{\prime} 01^{\prime \prime}$ W. A altitude média é de 109 m e o clima da região é subtropical úmido (Cfa), com verões muito quentes, segundo a classificação de Köppen. O solo da área experimental pertence à unidade de mapeamento Alto das Canas, sendo um argissolo vermelho distrófico latossólico (EMBRAPA, 1999).

Os tratamentos testados foram: Pastagem cultivada de milheto (PCM); pastagem natural (PN) e pastagem natural melhorada (PNM), distribuídos em delineamento inteiramente casualisado com duas repetições de área. Foram utilizadas áreas de 4 hectares para o tratamento PCM; 8 hectares para PN e 4,8 hectares para PNM.

Na área do tratamento PNM, foi realizada a correção da acidez do solo no início do mês de maio de 2004, sendo aplicadas três t ha-1 de calcário. A introdução das espécies hibernais ocorreu no dia 18/ 05/2004, por meio de semeadura direta, com densidade de 38kg ha-1 de sementes de azevém anual (Lolium multiflorum Lam.) cv. "Comum” semeadas em linhas, $5 \mathrm{~kg} \mathrm{ha}^{-1}$ de trevo vermelho (Trifolium pratense $\mathrm{L}$.) cv. “E-116” e de 8kg ha-1 de cornichão (Lotus corniculatus 
L.) cv. “São Gabriel” semeadas a lanço. Não foi utilizado herbicida para controle da vegetação natural, uma vez que, no dia da semeadura, a pastagem natural apresentava baixa massa de forragem. A adubação ocorreu por ocasião da semeadura, utilizando-se $350 \mathrm{~kg}$ ha $^{-1}$ da fórmula 02-25-25 (NPK). A PCM foi implantada pelo sistema de semeadura direta, com dessecação prévia da área com 3 litros ha ${ }^{-1}$ de glifosato. A semeadura, em linhas, foi realizada em 13/12/2004, utilizando-se $40 \mathrm{~kg} \mathrm{ha}^{-1}$ de sementes. A adubação foi de $250 \mathrm{~kg} \mathrm{ha}^{-1}$ da fórmula 05-25-25 e, em cobertura, foram utilizados $90 \mathrm{~kg} \mathrm{ha}^{-1}$ de nitrogênio (N) na forma de uréia, em duas aplicações (13/01 e 15/03).

Foram utilizadas 18 cordeiras-testes, por tratamento e número variável de animais reguladores. Foram utilizados cordeiros machos e vacas de corte como animais reguladores. As cordeiras utilizadas eram da raça Corriedale, com idade média de cinco meses, peso vivo médio de 25,6kg e escore corporal médio de três unidades, ao início do experimento. O período de pastejo foi de 29 de janeiro a 14 de abril de 2005, sendo caracterizado por forte estiagem. No período de janeiro a março, a precipitação foi de $164 \mathrm{~mm}$, sendo $44 \mathrm{~mm}$ no segundo dia após o início do experimento. Essa precipitação total ficou $46 \%$ abaixo da precipitação normal (305mm) para esses meses do ano em São Gabriel (MATZENAUER et al., 2002).

O método de pastejo foi contínuo, com taxa de lotação variável, utilizando a técnica de animais reguladores (MOTT \& LUCAS, 1952), com o objetivo inicial de manter uma oferta de $10 \%$ (10kg de MS 100 kg-1 de PV). Em função do agravamento da estiagem, procurou-se manter uma quantidade de folhas que permitisse boa disponibilidade e qualidade de forragem para o máximo desempenho animal, optando-se por aproximar a oferta de lâminas foliares verdes da oferta originalmente pretendida . As ofertas de forragem médias foram de 22,8; 30,6 e 33kg de MS $100 \mathrm{~kg}^{-1}$ de PV para PCM, PN e PNM, respectivamente. As ofertas médias de lâminas foliares verdes ficaram em 9,1; 14,1 e 9,7 kg de MS $100 \mathrm{~kg}^{-1}$ de PV para PCM, PN e PNM, respectivamente.

A massa de forragem (MF) foi estimada nos dias 29/01, 23/02, 17/03 e 14/04/2005, pelo método de estimativa visual com dupla amostragem (MANNETJE, 2000). Essa estimativa visual foi realizada em 20 quadros de $0,25 \mathrm{~m}^{2}$ por piquete, sendo que, em cinco destes, o material foi cortado rente ao solo. A partir das amostras cortadas, foram retiradas duas subamostras para determinação dos componentes: lâmina de folha verde, colmo + bainha e material morto da forragem disponível, sendo determinados por meio de separação manual e secagem a $60^{\circ} \mathrm{C}$ em estufa com ventilação forçada até peso constante. A partir de sua percentagem nas amostras, foi possível obter a quantidade de matéria seca de lâmina de folha verde (MSFV, kg ha-1), quantidade de colmo + bainha (MSC, $\mathrm{kg} \mathrm{ha}^{-1}$ ) e a quantidade de material morto (MSMM, kg ha-1) disponível para cada período estudado. As avaliações de taxa de acúmulo de MS foram feitas com três gaiolas de exclusão de pastejo por repetição empregando-se o método do triplo emparelhamento (MORAES et al., 1990), com avaliações nos dias 29/01, 23/02, 17/03 e 14/ 04/2005.

Os animais-teste e reguladores foram pesados nos dias 29/01, 23/02, 17/03 e 14/04/2005, sendo as pesagens precedidas de um período de jejum de sólidos e líquidos de 12 horas, para obtenção da evolução do peso vivo (PV), ganho médio diário (GMD) e cálculo da carga animal (CA). A CA por período foi calculada usando-se os pesos médios dos animaisteste e reguladores. Estes tiveram seu peso multiplicado pelo número de dias que permaneceram na pastagem e dividido pelo número de dias do período avaliado. $\mathrm{O}$ GMD foi estimado por meio da variação de peso dos animais-teste ao longo dos períodos, dividido pelo número de dias dos respectivos períodos de avaliação. Juntamente às pesagens, foi avaliado o escore corporal (EC), seguindo a metodologia descrita por RIBEIRO et al. (2003).

Foram coletadas amostras de forragem em cada repetição dos tratamentos nos dias 16/02, 10/03 e 05/04/2005, utilizando-se a técnica de simulação de pastejo animal. As amostras coletadas foram submetidas à pré-secagem em estufa com ventilação forçada a $55-60{ }^{\circ} \mathrm{C}$ até peso constante. Após isso, foram moídas em moinho tipo "Willey” com peneira de 1mm, identificadas e armazenadas em potes plásticos. Foram determinados os teores de proteína bruta (PB) (AOAC, 1995), fibra em detergente neutro (FDN), segundo a metodologia de ROBERTSON \& VAN SOEST (1981), modificada por KOMAREK (1993), e a determinação da fibra em detergente ácido (FDA) segundo a metodologia de GOERING \& VAN SOEST (1970). Foi conduzido ainda um ensaio para determinar as características de degradação das pastagens utilizando-se a técnica de produção de gases in vitro (MAURÍCIO et al., 1999).

Os dados foram submetidos à análise de variância e as médias comparadas pelo teste de Tukey, utilizando-se o programa computacional SAS (2001).

\section{RESULTADOS E DISCUSSÃO}

Observando-se os resultados apresentados na tabela 1 , verifica-se diferença $(\mathrm{P}=0,0001)$ para massa de forragem. $\mathrm{O}$ tratamento PNM apresentou valores 
superiores de massa de forragem aos demais tratamentos. Tal fato pode ser atribuído à grande quantidade de material morto presente na forragem disponível, proveniente em grande parte do azevém, que foi a principal espécie introduzida. Evidencia-se também diferença significativa $(\mathrm{P}=0,0117)$ no valor médio de massa de lâminas foliares verdes, sendo a PNM superior aos demais tratamentos, o que não foi verificado na comparação dentro de cada período. Entretanto, em valores percentuais, observa-se que a PNM tem a menor proporção de folhas em relação aos demais tratamentos. Na média final, também houve diferença $(\mathrm{P}=0,0004)$ na massa de colmos, sendo a PCM superior à $\mathrm{PN}$ e à PNM. Esta diferença pode ser justificada pelas características morfológicas do milheto, que apresenta colmos eretos, cheios e glabros. (HERINGER, 1995).

Foi observada diferença significativa $(\mathrm{P}=0,0010)$ para CA(Tabela 2), sendo que o tratamento PCM apresentou valores superiores de carga no primeiro período e na média final. Tal fato pode ser justificado pela elevada taxa de acúmulo da PCM verificada no primeiro período (Tabela 1). Já no segundo período, houve redução da CA em todos os tratamentos em função do agravamento da estiagem nesse período. A CA média de $914 \mathrm{~kg}$ de $P V$ ha $^{-1}$ foi semelhante às cargas utilizadas por CASTRO (2002) em pastagem de milheto manejada com $10 \mathrm{~cm}$ de altura, num período semelhante ao deste experimento, e a CA média de $261 \mathrm{~kg}$ de $\mathrm{PV} \mathrm{ha}^{-1}$ utilizada na PN foi semelhante à carga de $237 \mathrm{~kg}$ de PV ha $^{-1}$ verificada em pastagem natural por RIZO et al. (2004). SOARES et al. (2006), trabalhando com novilhas de sobreano em pastagem natural melhorada com introdução de trevo branco, trevo vermelho e cornichão, utilizou carga média de $437 \mathrm{~kg}$ de PV ha-1 para uma massa de forragem de $1752 \mathrm{~kg}$ de $\mathrm{MS} \mathrm{ha}^{-1}$, valor de carga animal próximo dos $467 \mathrm{~kg}$ de $\mathrm{PV}$ ha $^{-1}$ utilizado no tratamento PNM para uma massa de forragem média de 2.592kg de $\mathrm{MS} \mathrm{ha}^{-1}$.

A PCM também apresentou valores de GMD superiores $(\mathrm{P}=0,0001)$ aos dos demais tratamentos (Tabela 2), o que pode ser justificado principalmente pela maior proporção de folhas na massa de forragem em relação aos demais tratamentos (Tabela 1) e pela maior qualidade da pastagem (Tabela 2). Com relação à proporção de lâminas foliares, observa-se uma vantagem da PCM de quase o dobro em relação à PNM, no segundo período. Quanto aos indicadores de qualidade, PCM apresentou valores superiores de PB e inferiores de FDN e FDA, em todos os períodos. Essas diferenças podem ser atribuídas ao fato de o milheto ser uma planta anual com reconhecida tolerância ao estresse hídrico (HERINGER, 1995). O valor médio de $0,151 \mathrm{~kg} \mathrm{dia}^{-1}$ foi semelhante ao de $0,150 \mathrm{~kg} \mathrm{dia}^{-1}$ registrado por ROCHA et al. (2000) com cordeiras cruzas Texel x Ideal, em pastagem de milheto com oferta média de 19\%. Já CASTRO (2002) observou valores máximos de GMD de 125,5g dia-1 com cordeiros em pastagem de milheto na condição de $26,3 \%$ de oferta de forragem. No tratamento PN, o valor médio de $0,053 \mathrm{~kg} \mathrm{dia}^{-1}$ foi inferior aos observados por SIQUEIRA et al. (1984), que verificaram ganhos de $0,087 \mathrm{~kg} \mathrm{dia}^{-1} \mathrm{em}$ cordeiras ao pé da mãe da raça Ideal e de $0,093 \mathrm{~kg} \mathrm{dia}^{-1}$ em cordeiras cruzas Texel x Ideal criadas em pastagem nativa. $\mathrm{O}$ baixo desempenho médio dos animais no tratamento PNM pode ser explicado pela estiagem ocorrida e pela grande quantidade de material morto (acima de 60\%) presente na forragem disponível (Tabela 1), o que dificulta a ação seletiva dos animais. Entretanto, no primeiro período, quando a estiagem não era tão intensa e existia boa contribuição das leguminosas introduzidas, o GMD de $0,131 \mathrm{~kg} \mathrm{dia}^{-1}$ foi semelhante ao da PCM e superior ao da PN.

As cordeiras do tratamento PCM chegaram a um peso vivo final muito próximo ao de ovelhas adultas da raça Corriedale, refletindo os ganhos individuais observados e o incremento de peso no período, destacando-se que a PCM, mesmo em situação de estresse hídrico, proporciona ganhos satisfatórios para antecipação da idade de encarneiramento.

Em todos os tratamentos, os valores de EC ficaram acima de 2,5 unidades, sugerido por RIBEIRO et al. (2003) como escore crítico para garantir uma taxa de prenhez aceitável. Esses autores avaliaram a condição corporal média no início do encarneiramento e sua influência na taxa de prenhez em um rebanho de ovelhas Corriedale criadas em campo nativo e obsevaram que, conforme aumenta a condição corporal, aumenta a percentagem de prenhez, atingindo o valor máximo de $98 \%$ na categoria de ovelhas com condição corporal de 4,0 unidades, com uma tendência de diminuição da taxa de prenhez com valores mais altos de condição corporal. No presente trabalho, as cordeiras da PCM apresentaram escore corporal final mais próximo ao valor obtido por RIBEIRO et al. (2003) para uma máxima taxa de prenhez.

Como comentado anteriormente, a PCM apresentou maiores valores de proteína bruta e menores de FDN e FDA (Tabela 2) do que a PN e a PNM. O valor médio verificado de $23,7 \%$ de PB na PCM concorda com os dados levantados por CASTRO (2002), que encontrou valores que variaram de 20,2 a $28,2 \%$ de proteína bruta em lâminas foliares de milheto coletadas por simulação de pastejo, o que permite ressaltar que o material coletado, e que era preferencialmente consumido pelos animais, era composto principalmente por lâminas foliares jovens de melhor qualidade. Os valores de PB e FDN da PN ficaram próximos daqueles 
Tabela 1 - Massa de forragem (kg de MS ha ${ }^{-1}$ ), massa de lâminas foliares verdes ( $\mathrm{kg}_{\text {de MSFV ha }}{ }^{-1}$ ), massa de colmo kg de MSC ha ${ }^{-1}$ ), massa de material morto ( $\mathrm{kg}$ de MS de MM ha ${ }^{-1}$ ), proporção lâmina foliar/colmo/material morto (\%) e taxa de acúmulo (kg de MS ha ${ }^{-1}$ $\left.\operatorname{dia}^{-1}\right)$.

\begin{tabular}{|c|c|c|c|c|}
\hline \multirow{2}{*}{ Tratamento } & \multicolumn{3}{|c|}{ Períodos } & \multirow{2}{*}{ Média } \\
\hline & 29/01 а 23/02 & 24/02 a 17/03 & $18 / 03$ a $14 / 04$ & \\
\hline \multicolumn{5}{|c|}{ Massa de forragem (kg de MS ha ${ }^{-1}$ ) } \\
\hline PCM & $1151,8 b^{*}$ & $820,0 \mathrm{~b}$ & 936,9 & $969,5 \mathrm{~b}$ \\
\hline PN & $1436,2 \mathrm{~b}$ & 1462 b & 982,9 & $1293,7 \mathrm{~b}$ \\
\hline PNM & 2892,9 a & 2928,5 a & 1955,8 & 2592,4 a \\
\hline \multicolumn{5}{|c|}{ Massa de lâminas foliares verdes ( $\mathrm{kg}$ de MSFV ha-1) } \\
\hline PCM & 699,1 & 364,4 & 390,7 & $484,7 \mathrm{~b}$ \\
\hline $\mathrm{PN}$ & 598,7 & 615,9 & 455,9 & $556,8 \mathrm{~b}$ \\
\hline PNM & 920,8 & 764,1 & 535,6 & $740,2 \mathrm{a}$ \\
\hline \multicolumn{5}{|c|}{ Massa de colmos (kg de MSC ha' ${ }^{-1}$ ) } \\
\hline PCM & 372,7 & 329,2 & 442,7 & 381,5 a \\
\hline PN & 170,8 & 189,9 & 96,5 & $152,4 \mathrm{~b}$ \\
\hline PNM & 232,2 & 235,1 & 138,6 & $201,9 \mathrm{~b}$ \\
\hline \multicolumn{5}{|c|}{ Massa de material morto (kg de MS de $\mathrm{MM} \mathrm{ha}^{-1}$ ) } \\
\hline PCM & $80,0 \mathrm{~b}$ & $126,4 \mathrm{~b}$ & $103,5 \mathrm{~b}$ & 103,3 c \\
\hline $\mathrm{PN}$ & $666,6 \mathrm{~b}$ & $656,1 \mathrm{~b}$ & $430,4 \mathrm{~b}$ & $584,4 \mathrm{~b}$ \\
\hline PNM & 1740,0 a & 1929,3 a & 1281,5 a & $1650,3 \mathrm{a}$ \\
\hline \multicolumn{5}{|c|}{ Proporção lâmina foliar/colmo/material morto (\%) } \\
\hline PCM & $61 / 32 / 7$ & $44 / 40 / 16$ & $42 / 47 / 11$ & $50 / 39 / 11$ \\
\hline $\mathrm{PN}$ & $42 / 12 / 46$ & $42 / 13 / 45$ & $46 / 10 / 44$ & $43 / 12 / 45$ \\
\hline PNM & $32 / 8 / 60$ & 26/8/66 & $27 / 7 / 66$ & 29/8/63 \\
\hline \multicolumn{5}{|c|}{ Taxa de acúmulo (kg de MS ha ${ }^{-1} \operatorname{dia}^{-1}$ ) } \\
\hline PCM & 152,3 a & 28,3 & 89,5 a & 90,0 a \\
\hline PN & $0,0 \mathrm{~b}$ & 0,0 & $33,2 \mathrm{~b}$ & $14,7 \mathrm{~b}$ \\
\hline PNM & $46,9 \mathrm{~b}$ & 0,0 & $24,1 \mathrm{~b}$ & $23,7 \mathrm{~b}$ \\
\hline
\end{tabular}

* Letras distintas na mesma coluna indicam diferença entre os tratamentos $(\mathrm{P}=0,05)$.

levantados por SILVEIRA et al. (2005). A PNM se apresentou semelhante à $\mathrm{PN}$ nos valores de $\mathrm{PB}, \mathrm{FDN}$ e FDA, em virtude da baixa contribuição das espécies hibernais introduzidas e da estiagem ocorrida ao longo do período experimental. Os valores médios de PB e FDA da PNM ficaram próximos dos verificados por FISCHER et al. (2005) em uma pastagem natural melhorada com sobre-semeadura de Lotus subbiflorus.

O volume final de gás, a taxa de degradação e o tempo de colonização foram bem correlacionados com a composição química e os ganhos de peso observados, sendo melhores para a PCM. Em pastagem de milheto mantida em duas alturas de pastejo (20-30 e 40-50cm), GENRO et al. (2005) verificaram valores de produção de gás entre 57 a 162 ml, tempo de colonização entre 0,69 e 2,79 horas e taxa de degradação entre 2,14 e $4,13 \%$ horas $^{-1}$. No presente trabalho, foi observado um GMD médio de $0,49 \%$ do PV, superior ao obtido por SANTOS et al. (2003), com novilhas de 14 meses de idade, de 0,33\% do PV. Esta comparação em termos percentuais do PV permite cotejar desempenhos de espécies de pesos metabólicos diferentes, como os ovinos e bovinos. Essas referências são apresentadas pela escassez de trabalhos com esses indicadores de qualidade da forragem. Estes valores de desempenho animal de SANTOS et al. (2003) são do mesmo experimento de GENRO et al. (2005), o que pode justificar os valores de volume final de gás, a taxa de degradação e o tempo de colonização, que foram melhores neste trabalho, em relação aos dados de GENRO et al. (2005). Existe uma alta correlação entre o volume de gás e a perda de MS pela digestão. Assim, quanto maior o volume de gás e menor o tempo de colonização, maior será a taxa de degradação e, em conseqüência, menor será o tempo de permanência do alimento no rúmen, o que leva a um maior consumo e melhor desempenho (MERTENS, 1993). 
Tabela 2 - Carga animal $\left(\mathrm{kg}\right.$ de $\left.\mathrm{PV} \mathrm{ha}^{-1}\right)$, ganho médio diário $\left(\mathrm{kg} \mathrm{dia}^{-1}\right)$, peso vivo médio final $\left(\mathrm{kg}\right.$ de $\mathrm{PV}$ animal $\left.{ }^{-1}\right)$, escore corporal final (EC), proteína bruta (\%), fibra em detergente neutro (\%), fibra em detergente ácido (\%), volume final de gás (ml após 96 horas), taxa de degradação $\left(\%\right.$ hora $\left.^{-1}\right)$ e tempo de colonização (horas).

\begin{tabular}{|c|c|c|c|c|}
\hline \multirow{2}{*}{ Tratamento } & \multicolumn{3}{|c|}{ Períodos } & \multirow{2}{*}{ Média } \\
\hline & Período 1 & Período 2 & Período 3 & \\
\hline \multicolumn{5}{|c|}{ Carga animal (kg de $\left.\mathrm{PV} \mathrm{ha}^{-1}\right)$} \\
\hline PCM & $2031,2 a^{*}$ & 190,9 & 521,6 & 914,6 a \\
\hline PN & $327,0 \mathrm{~b}$ & 125,6 & 330,7 & $261,1 \mathrm{~b}$ \\
\hline PNM & $582,6 \mathrm{~b}$ & 246,8 & 572,4 & $467,3 \mathrm{~b}$ \\
\hline \multicolumn{5}{|c|}{ Ganho médio diário $\left(\mathrm{kg} \mathrm{dia}^{-1}\right)$} \\
\hline PCM & 0,194 a & 0,131 a & $0,127 \mathrm{a}$ & $0,151 \mathrm{a}$ \\
\hline PN & $0,050 \mathrm{~b}$ & $0,084 \mathrm{ab}$ & $0,025 \mathrm{~b}$ & $0,053 \mathrm{~b}$ \\
\hline PNM & 0,131 а & $0,051 \mathrm{~b}$ & $-0,007 b$ & $0,058 \mathrm{~b}$ \\
\hline \multicolumn{5}{|c|}{ Peso vivo final $\left(\mathrm{kg}\right.$ de $\mathrm{PV}$ animal $\left.^{-1}\right)$} \\
\hline PCM & $30,0 \mathrm{a}$ & 32,7 & $36,1 \mathrm{a}$ & - \\
\hline PN & $26,3 \mathrm{~b}$ & 28,1 & $28,8 \mathrm{~b}$ & - \\
\hline PNM & $29,7 \mathrm{a}$ & 30,8 & $30,6 \mathrm{~b}$ & - \\
\hline \multicolumn{5}{|c|}{ Escore corporal final (EC) } \\
\hline PCM & 3,7 a & 3,5 & 3,7 a & - \\
\hline $\mathrm{PN}$ & $3,0 \mathrm{~b}$ & 3,2 & $3,1 \mathrm{~b}$ & - \\
\hline PNM & 3,5 a & 3,3 & $3,1 \mathrm{~b}$ & - \\
\hline \multicolumn{5}{|c|}{ Proteína bruta (\%) } \\
\hline PCM & 22,35 a & 24,79 a & 24,00 a & 23,71 a \\
\hline $\mathrm{PN}$ & $11,48 \mathrm{~b}$ & $11,04 \mathrm{~b}$ & $13,83 \mathrm{~b}$ & $12,12 \mathrm{~b}$ \\
\hline PNM & $11,56 \mathrm{~b}$ & $12,62 \mathrm{~b}$ & $18,80 \mathrm{ab}$ & $14,33 \mathrm{~b}$ \\
\hline \multicolumn{5}{|c|}{ Fibra em detergente neutro (\%) } \\
\hline PCM & $43,84 \mathrm{~b}$ & $56,82 \mathrm{~b}$ & $51,12 \mathrm{~b}$ & $50,59 \mathrm{~b}$ \\
\hline PN & 65,69 a & 66,72 a & 69,53 a & 67,31 a \\
\hline PNM & 67,12 a & 66,70 a & 63,75 a & 65,86 a \\
\hline \multicolumn{5}{|c|}{ Fibra em detergente ácido (\%) } \\
\hline PCM & $21,64 \mathrm{~b}$ & $27,55 \mathrm{~b}$ & $27,65 \mathrm{~b}$ & $25,61 \mathrm{~b}$ \\
\hline $\mathrm{PN}$ & 31,18 a & 32,55 a & 33,44 a & 32,39 a \\
\hline PNM & 32,19 a & $32,12 \mathrm{ab}$ & $31,26 \mathrm{ab}$ & 31,86 a \\
\hline \multicolumn{5}{|c|}{ Volume final de gás (ml após 96 horas) } \\
\hline PCM & 192,95 & 190,85 & 177,80 & $187,20 \mathrm{a}$ \\
\hline $\mathrm{PN}$ & 163,15 & 142,40 & 135,35 & $146,96 \mathrm{~b}$ \\
\hline PNM & 161,00 & 148,00 & 134,45 & $147,82 \mathrm{~b}$ \\
\hline \multicolumn{5}{|c|}{ Taxa de degradação $\left(\%\right.$ hora $\left.^{-1}\right)$} \\
\hline PCM & 2,80 & $3,41 \mathrm{a}$ & $3,26 \mathrm{a}$ & 3,16 a \\
\hline PN & 2,10 & $2,36 \mathrm{~b}$ & $2,15 b$ & $2,20 \mathrm{~b}$ \\
\hline PNM & 2,02 & $2,49 \mathrm{ab}$ & $2,59 \mathrm{ab}$ & $2,37 \mathrm{~b}$ \\
\hline \multicolumn{5}{|c|}{ Tempo de colonização (horas) } \\
\hline PCM & 4,25 & 6,75 & 5,60 & $5,53 \mathrm{~b}$ \\
\hline PN & 11,30 & 12,65 & 12,30 & 12,08 a \\
\hline PNM & 11,55 & 12,90 & 11,50 & 11,98 a \\
\hline
\end{tabular}

*Letras distintas na mesma coluna indicam diferença entre os tratamentos $(\mathrm{P}=0,05)$.

\section{CONCLUSÕES}

A pastagem de milheto é uma alternativa para incrementar a carga animal e o ganho de peso em sistemas de recria de ovinos, no Rio Grande do Sul. A pastagem cultivada de milheto apresenta qualidade nutricional superior se comparada à pastagem natural e à pastagem natural melhorada.

\section{REFERÊNCIAS}

ASSOCIATION OF OFFICIAL ANALYTICAL CHEMISTS AOAC. Official methods of analysis. 16.ed. Washington, DC., 1995. 2000p.

Ciência Rural, v.38, n.1, jan-fev, 2008. 
BOLDRINI, I.I. Campos do Rio Grande do Sul: caracterização fisionômica e problemática ocupacional. Porto Alegre: Instituto de Biociências, 1997. 39p. (Boletim do Instituto de Biociências, 56).

CARÁMBULA, M. Pasturas naturales mejoradas. Montevideo: Hemisferio Sur, 1997. 524p.

CARVALHO, P.C. de F. et al. Produção animal no bioma campos sulinos. Revista Brasileira de Zootecnia, Viçosa, v.35, Sup. Esp, p.156-202, 2006.

CASTRO, C.R. de C. Relações planta-animal em pastagem de milheto (Pennisetum americanum (L.) Leeke.) manejada em diferentes alturas com ovinos. 2002. 185f. Dissertação (Mestrado em Zootecnia) - Programa de Pós-graduação em Zootecnia, Universidade Federal do Rio Grande do Sul

EMBRAPA. Centro nacional de pesquisa de solos (Rio de Janeiro, RJ). Sistema brasileiro de classificação de solos. Brasília: Embrapa Produção de informação, Rio de janeiro: Embrapa Solos, 1999. 412p.

FISCHER, V. et al. Ganho de peso de novilhos mantidos em pastagem natural na encosta do sudeste do Rio Grande do Sul, recebendo níveis crescentes de suplementação energética. Revista Brasileira de Zootecnia, Viçosa, v.34, n.1, p.159166, 2005.

GENRO, T.C.M. et al. Cinética de degradação da matéria seca da pastagem de milheto mantida com duas alturas. In: REUNIÃO ANUAL DA SOCIEDADE BRASILEIRA DE ZOOTECNIA, 42., 2005, Goiânia, GO. Anais... Goiânia: Sociedade Brasileira de Zootecnia, 2005. CD-rom.

GOERING, H.K.; VAN SOEST, P.J. Forage fiber analysis (apparatus, reagents, procedures and some applications). Washington, DC: Agric. Res. Seervice, U.S. Dep. Agric., 1970. 379p.

HERINGER, I. Efeitos de níveis de nitrogênio sobre a dinâmica de uma pastagem de milheto (Pennisetum americanum (L.) Leeke) sob pastejo. 1995. $183 f$. Dissertação (Mestrado em Zootecnia) - Curso de Pós-graduação em Zootecnia, Universidade Federal de Santa Maria.

KOMAREK, A.R. A filter bag procedure for improved efficiency of fiber analysis. Journal of Dairy Science, Palo Alto, v.76, supplement 1, p.250, 1993.

MANNETJE, L'.T. Measuring biomass of grassland vegetation In: MANNETJE, L'.T.; JONES, R.M. Field and laboratory methods for grassland and animal production research. Wallingford: CAB International, 2000. Cap.7, p.151-178.

MATZENAUER, R. et al. Consumo de água e disponibilidade hídrica para milho e soja, no Rio Grande do Sul. Porto Alegre: FEPAGRO, 2002. 105p. (BOLETIM FEPAGRO, 10).
MAURICIO, R.M. et al. A semi-automated in vitro gas production technique for ruminant feedstuff evaluation. Animal Feed Science and Technology, Reading, v.79, n.4, p.321330, 1999

MERTENS, D.R. Rate and extent of digestion. In: FORBES, J.M.; FRANCE, J. (Eds.). Quantitative aspects of ruminant digestion and metabolism. Cambridge, England: Commonwealth Agricultural Bureaux, Cambridge University. 1993. p.13-51.

MONTOSSI, F. et al. Utilização de pastagens em sistemas pecuários (Utilización de mejoramientos de campo em pastoreo mixto para engorde de novillos y corderos en Uruguay). In: REUNIÃO ANUAL DA SOCIEDADE BRASILEIRA DE ZOOTECNIA, 40., 2003, Santa Maria, RS. Anais... Santa Maria, RS: Sociedade Brasileira de Zootecnia, 2003. CD-rom.

MOOJEN, E.L. et al. Produção animal em pastagem de milheto sob diferentes níveis de nitrogênio. Pesquisa Agropecuária Brasileira, Brasília, v.34, n.11, p.2145-2149, 1999.

MORAES, A. de. et al. Comparação de métodos de estimativa de taxas de crescimento em uma pastagem submetida a diferentes pressões de pastejo. In: REUNIÃO ANUAL DA SOCIEDADE BRASILEIRA DE ZOOTECNIA, 27., 1990, Piracicaba, SP. Anais... Piracicaba: FEALQ, 1990. p.332.

MOTT, G.O.; LUCAS, H.L. The desing conduct and interpretation of grazing trials in cultivated and improved pastures, Pensylvania. In: INTERNATIONAL GRASSLAND CONGRESS, 6., 1952, Pensylvania. Proceedings... Pensylvania: State College, 1952. p.1380-1395.

NABINGER, C. Manejo de campo nativo na região sul do Brasil e a viabilidade do uso de modelos. In: SIMPÓSIO INTERNACIONAL EM PRODUÇÃO ANIMAL, 2., 2006, Santa Maria, RS. Anais... Santa Maria: Departamento de Zootecnia, 2006. CD-rom.

RIBEIRO, L.A.O. et al. Relação entre a condição corporal e a idade das ovelhas no encarneiramento com a prenhez. Ciência Rural, Santa Maria, v.33, n.2, p.357-361, 2003.

RIZO, L.M. et al. Desempenho de pastagem nativa e pastagem sobre-semeada com forrageiras hibernais com e sem glifosato. Ciência Rural, Santa Maria, v.34, n.6, p.1921-1926, 2004.

ROBERTSON, J.B.; VAN SOEST, P.J. The detergent system of analysis and its application to human foods. In: JAMES, W.P.T.; THEANDER, O. (Eds.). The analysis of dietary fiber in food. New York: Marcel Dekker, 1981. p.123-158.

ROCHA, M.G. da. et al. Desempenho de ovinos em pastagem de milheto sob diferentes ofertas de forragem. In: REUNIÃO ANUAL DA SOCIEDADE BRASILEIRA DE ZOOTECNIA, 37., 2000, Viçosa, MG. Anais... Viçosa: Sociedade Brasileira de Zootecnia, 2000. CD-rom.

SANTOS, D.T. dos. et al. Produção animal e retorno econômico em pastagem de milheto (Pennisetum americanum (L.) Leeke) 
manejada sob diferentes alturas. In: REUNIÃO ANUAL DA SOCIEDADE BRASILEIRA DE ZOOTECNIA, 40., 2003, Santa Maria, RS. Anais... Santa Maria: Sociedade Brasileira de Zootecnia, 2003. CD-rom.

SANTOS, D.T. dos et al. Suplementos energéticos para recria de novilhas de corte em pastagens anuais: Desempenho animal. Revista Brasileira de Zootecnia, Viçosa, v.34, n.1, p.209219, 2005.

SAS INSTITUTE. System for Microsoft Windows: release 8.2. Cary, 2001. CD.
SILVEIRA, V.C.P. et al. Qualidade da pastagem nativa obtida por diferentes métodos de amostragem e em diferentes solos na Apa do Ibirapuitã, Brasil. Ciência Rural, Santa Maria, v.35, n.3, p.582-588, 2005.

SIQUEIRA, E.R. de. et al. Desempenho de cordeiros machos e fêmeas da raça Ideal e cruzas Texel x Ideal, criados em pastagem nativa. Pesquisa Agropecuária Brasileira, Brasília, v.19, n.12, p.1523-1528, 1984.

SOARES, A.B. et al. Efeitos de diferentes intensidades de pastejo em pastagem nativa melhorada sobre o desempenho animal. Revista Brasileira de Zootecnia, Viçosa, v.35, n.1, p.7583, 2006. 